\title{
"Como e quando começamos a falar Português?" A história do deslocamento linguístico na Amazônia
}

OPEN ACCESS

EDITADO POR

Raquel Freitag

AVALIADO POR

Norma Almeida

SOBRE OS AUTORES

Bárbara Heliodora Santos Contribuiu com José de Rezende

Costa Neto. Papéis: visualização, escrita - rascunho original.

José de Rezende Costa Neto

Contribuiu com Bárbara

Heliodora Santos. Papéis: visualização, escrita - rascunho original.

DATAS

Recebido: 10/07/2020

Aceito: 25/07/2020

Publicado: 30/07/2020

COMO CITAR

Santos, B. H.; Costa Neto, J. R.

(2020).

"Como e quando começamos a falar Português?" A história do

deslocamento linguístico na Amazônia. Revista da Abralin,

v. 19, n. 2, p. 1-5, 2020.
Bárbara Heliodora SANTOS (D)

Universidade de Brasília (UnB)

José de Rezende COSTA NETOD

Universidade Federal de Goiás (UFG)

\section{RESUMO}

José Ribamar Bessa Freire visita línguas indígenas que já se perderam, por meio da história da Língua Geral Amazônica (LGA), a partir do testemunho documental de acervos históricos. Elegendo o campo teórico da História Social da Linguagem, Bessa Freire investiga os aspectos externos que promoveram a hegemonia da Língua Portuguesa e o declínio de centenas de línguas indígenas. Das 1300 línguas faladas no Brasil antes da chegada dos europeus, restam 274 autodeclaradas recenseadas pelo IBGE em 2010, porém, se submetidas a critérios linguísticos, subsistiriam menos de 180 línguas. A situação pandêmica proporcionada pelo Covid-19 faz soar o alerta, visto que indígenas têm perdido suas vidas, em especial os anciãos portadores de saberes inestimáveis.

\section{ABSTRACT}

José Ribamar Bessa Freire visits indigenous languages that have already been lost, through the history of the Lingua Geral Amazônica (LGA), from the documentary testimony of historical collections. Electing the theoretical field of the Social History of Language, Bessa Freire investigates the external aspects that promoted the hegemony of the Portuguese language and the decline of hundreds of indigenous languages. Of the 1,300 


\section{REVISTA DA ABRALIN}

languages spoken in Brazil before the arrival of Europeans, there are 274 self-declared languages listed by IBGE in 2010, but if submitted to linguistic criteria, there would remain less than 180 languages. The pandemic situation provided by Covid-19 sounds the alarm, as indigenous people have lost their lives, especially the elders with invaluable knowledge.

\section{PALAVRAS-CHAVE}

Línguas indígenas. Língua Geral Amazônica. História Social da Linguagem.

\section{KEYWORDS}

Indigenous languages. Língua Geral Amazônica. Social History

of Language.

A conferência Línguas indígenas, línguas ameaçadas, apresentada por José Ribamar Bessa Freire, professor da Pós-Graduação em Memória Social da Universidade Federal do Estado do Rio de Janeiro, mostra-se de extrema importância, sobretudo neste momento, em que o Brasil e o mundo enfrentam uma séria epidemia. Partindo desse ponto, Bessa Freire começa a sua fala: com quase 65.000 mortos pelo novo coronavírus, centenas de vidas indígenas ajudam a compor essa estatística. Para tentarmos ser um pouco mais exatos, de acordo com a Articulação de Povos Indígenas do Brasil (Apib), que faz um levantamento independente dos casos de Covid-19 entre os indígenas brasileiros, a epidemia já afetou 127 povos indígenas, com 12.777 casos confirmados e 455 mortos ${ }^{1}$.

Entre os indígenas mortos, aponta Bessa Freire, muitos deles são anciãos e sábios. Isso significa, que, para além da morte dessas pessoas, línguas e saberes são perdidos, cantos e poesias desaparecem, culturas morrem. Pautado nisso, Bessa Freire defende, em sua fala, a necessidade de se conhecer a vida e a história das línguas e as políticas linguísticas que interferiram e interferem em seu destino.

"Como e quando começamos a falar Português?". Essa é a discussão básica que guia a fala de Bessa Freire em sua palestra e que guiou sua tese de doutorado, publicada em livro, cujo título é "Rio Babel: a história das línguas na Amazônia". Como campo teórico, Bessa Freire escolhe a História Social da Linguagem. Segundo ele, este é um campo promissor que requer cooperação interdisciplinar e cujo foco incide sobre a história externa das línguas, seus usos, suas funções. Nesse sentido, o palestrante procura identificar o porquê de algumas línguas expandirem-se, enquanto outras se retraem, chegando, até mesmo, à extinção. O método de tal área é a pesquisa documental em arquivos disponíveis. Desse método, abstrai-se a inevitável dicotomia entre o que é externo e interno à língua. Essa perspectiva dicotômica rende

1 Disponivel em: <https://covid19.socioambiental.org/?gclid=Cj0KCQjwgJv4BRCrARIsAB17JI5KoRPxJrXF9IVCgc1k6Tpm1hiiXVEMbxjRpqA2y_31HkKGSCR97qoaAuuCEALw_wcB>. Acesso em 09 jun. 2020. 


\section{REVISTA DA ABRALIN}

limitações à História Social da Linguagem, uma vez que o seu trabalho a leva à reconstituição dos testemunhos documentais sem, contudo, confrontá-los com a substância da língua.

A constatação de que havia mais de 1.300 línguas indígenas sendo faladas no período da colonização no que é hoje o território brasileiro, entre as quais, cerca de 700 línguas eram faladas só no que é hoje o território amazônico, parte do trabalho do linguista Čestmír Loukotka (1968). O linguista, na ausência de dados linguísticos, recorre a dados históricos para chegar a esse número, que muito se aproxima da estimativa feita por Rodrigues (2000), também baseada em dados históricos produzidos pelos primeiros portugueses ingressos no Brasil, o qual estimou a existência de 1.273 línguas indígenas no momento da colonização do território que hoje é o Brasil, dentre as quais, pelo menos, 495 eram faladas na região que hoje é a Amazônia brasileira.

Conforme o censo do IBGE de 2010, no momento atual, 274 línguas indígenas autodeclaradas são faladas no Brasil, embora especialistas, baseados em critérios linguísticos, apontem para um número entre 150 e 180 línguas (cf. Rodrigues (2005)). A diferença numérica entre o número de línguas indígenas existente no início da colonização e o número de línguas indígenas da atualidade leva Bessa Freire ao seguinte questionamento: como mais de 1.100 línguas foram perdidas em cinco séculos e como chegamos à hegemonia do Português? Por meio da história da chamada Língua Geral Amazônica (atualmente conhecida como Nheengatu), o linguista-historiador faz uma visitação a arquivos históricos para entender como e por que o Português tornou-se uma língua hegemônica; como as políticas linguísticas interferiram nessa hegemonia e na morte de centenas de outras línguas e qual é o Português resultante dos diversos contatos. Todos esses questionamentos são feitos ao mesmo tempo em que se pergunta o destino das línguas gerais que garantiam inteligibilidade entre o litoral e a Amazônia. O conferencista tem um especial cuidado em apresentar suas fontes e mostrar como elas foram questionadas. Para ele, documentos históricos devem ser interrogados.

A área que hoje constitui a Amazônia brasileira era e é um arquipélago de línguas, de tal modo que Padre Vieira a denominou de Rio Babel. Bessa Freire discute que a chegada do europeu significou uma ruptura nesse quadro de línguas. Historicamente, é possível remontar que a política linguística praticada pela Coroa Portuguesa incentivava o uso de línguas gerais que se opunham às línguas particulares e que eram compartilhadas em uma porção territorial, permitindo a comunicação interétnica na realidade plurilinguística do início da colonização. Tal política perdurou até a primeira metade do século XVIII, quando novas aspirações econômicas advindas do projeto pombalino impuseram o Português como língua do território brasileiro.

Entretanto, é a situação linguística do Amazonas, pertencente ao Estado do Grão Pará e Maranhão, durante o período colonial, que toma relevância na conferência. Segundo Bessa Freire, a formação de uma língua geral por esses locais poderia ter se dado antes mesmo do período colonial. Indígenas em situação de contato com outras etnias usavam o Tupinambá falado na Costa do Salgado, entre São Luís do Maranhão e Belém, para a comunicação. Os jesuítas teriam percebido que tal idioma permitia inteligibilidade entre diversas etnias e usado dessa língua para fins de catequese e de colonização. Sendo assim, Bessa Freire está, particularmente, interessado no deslocamento linguístico que fez desaparecer boa parte das 700 línguas faladas em toda a Amazônia e, em um primeiro momento, fez expandir uma 


\section{REVISTA DA ABRALIN}

língua geral e que veio, posteriormente, a desembocar na hegemonia do Português. Para dar conta do fenômeno, o palestrante perfaz o caminho em cinco momentos históricos.

O primeiro momento é o reconhecimento da realidade plurilinguística com mais de 700 línguas particulares usadas em todas as práticas sociais das comunidades. Segundo Bessa Freire, é nesse estágio que começa a se formar a língua geral, chamada por Rodrigues (1996) de Língua Geral Amazônica (LGA). Bessa Freire destaca que, neste período inicial, os indígenas são chamados de selvagens por serem capazes de se comunicar, tão somente, em pequenos grupos, por meio de suas línguas nativas. O segundo momento se dá quando os "índios selvagens" saíram compulsoriamente de suas aldeias requisitados como força de trabalho pela sociedade regional. Nesse contexto, houve diversos contatos com falantes de LGA, o que proporcionou um bilinguismo em língua vernácula (isto é, a sua língua materna) e em LGA. Ao selvagem, agora bilíngue, era dado o nome de "índio manso".

No terceiro momento, houve uma fixação generalizada de residência fora de suas aldeias de origem, em vilas e povoados, acarretando casamentos interétnicos, o que forçava o abandono das práticas sociais em língua vernácula e a interrupção de seu legado à sua descendência, que agora tinha, como língua materna, a LGA. Aos indígenas descendentes de tal situação dava-se o nome de "tapuias". No quarto momento, por volta de 1820, período que se inicia com a adesão do Grão Pará e Maranhão ao Brasil, força-se uma situação de bilinguismo em LGA e Português. Para a compreensão de tal período, deve-se ter em conta que a província anexada contava com 200.000 habitantes recenseados falantes de LGA, ao passo que o Brasil já contava com 4 milhões de habitantes majoritariamente falantes de Português. Agora, esse índio bilíngue em LGA e Português é chamado de "índio civilizado". No quinto momento, Bessa Freire ressalta, já no século XIX, o ciclo da borracha e a migração de mais de 500 mil nordestinos para a região do Amazonas, o que ocasiona o declínio da LGA com o deslocamento para o Português. Nesse último período, a LGA foi deixando de atuar nos espaços onde atuava e ficou restrita ao Alto Rio Negro, o que fez emergir uma situação de monolinguismo em Língua Portuguesa. Esse indígena monolíngue em Português foi chamado de "caboclo".

Como já mencionado, esse deslocamento linguístico ilustra o uso da LGA e da Língua Portuguesa em situação de contato. No entanto, como Bessa Freire afirma em sua palestra, o seu foco incide na história externa da língua. Nesse sentido, ainda existe um desafio para os linguistas que é o de entender como a LGA e o próprio Português modificaram-se internamente diante dessa situação de contato linguístico. Por isso, ainda é necessário que seja feito um trabalho minucioso de análise linguística da vasta documentação histórica existente, como as gramáticas de Anchieta (1595) e de Figueira (1621), por exemplo, no sentido de entender quais mudanças linguísticas, como fonológicas, morfológicas e sintáticas, fizeram com que o Tupinambá, falado pelos indígenas Tupinambá e usado, inicialmente, como língua de contato, sofreu para que a LGA, hegemônica até metade do século XIX, fosse considerada uma língua diferente do Tupinambá "original", da qual ela descende. Ainda, é preciso discutir quais mudanças o Nheengatu, descendente atual da LGA e língua dos povos Baré, Baniwa e Werekena, sofreu em relação ao Tupinambá, às línguas ancestrais dos povos que a adotaram como língua materna e ao Português. Ainda, é preciso investigar as transformações gramaticais da LGA, desde o Tupinambá, tendo em vista os diversos processos de substituição linguística aos quais essa língua foi submetida, 


\section{REVISTA DA ABRALIN}

bem como os efeitos do contato com o Português. Alguns passos nessa direção foram dados por Moore, Facundes e Pires (1993) e Cruz (2011), e em artigos que analisam diacronicamente as transformações sofridas pelo Nheengatu que o afasta tipologicamente das demais línguas Tupi-Guarani (cf., por exemplo, Cruz (2015); Magalhães, Cruz, Praça (2019).

\section{REFERÊNCIAS}

ANCHIETA, José de. Arte de gramática da língua mais usada na costa do Brasil. [edição fac-similar da 1a . ed. Coimbra: Antônio Mariz]. São Paulo: Loyolla, 1990[1595].

CRUZ, Aline da. Fonologia e Gramática do Nheengatú: a língua geral falada pelos povos Baré, Warekena e Baniwa. 1. ed. Utrecht, Países Baixos: LOT, 2011.

CRUZ, Aline da. The rise of number agreement in Nheengatu. Boletim do Museu Paraense Emílio Goeldi. Série Ciências Humanas, Belém, v. 10, p. 419-439, 2015.

FIGUEIRA, Luís. Arte da Língua Brasílica. Lisboa: Manuel da Silva, 1621. Disponível em: http://www.etnolinguistica.org/biblio:figueira-1621-arte. Acesso em: 6 jul.2020.

FREIRE, José Ribamar Bessa. Rio Babel: a história social das línguas na Amazônia. Rio de Janeiro: Ed. UERJ/ATLANTICA, 2004.

LíNGUAS Indígenas, Línguas Ameaçadas. Conferência apresentada por José Ribamar Bessa Freire [s.l., s.n], 2020.1 vídeo (1h 44min 15s). Publicado pelo canal da Associação Brasileira de Linguística. Disponível em https://www.you-

tube.com/watch?v=aBn8HfXjwIo\&t=4109s. Acesso em: 05 jul.2020.

LUOKOTTA, Cestmir. Classification of South American Indian Languages. Latin American Center. UCLA: Los Angeles, USA, 1968.

MAGALHÃES, Marina; PRAÇA, Walkíria; CRUZ, Aline da. Gradação da omnipredicatividade na família Tupi-Guarani. FORMA Y FUNCION, v. 32, p. 151-189, 2019.

MOORE, Denny; FACUNDES, Sidney; PIRES, Nádia. Nheengatu (LGA), it's history, and effects of language contact. Survey of California and Other Indian Languages, Berkeley, v. 8, p. 93-118, 1993.

RODRIGUES, Aryon Dall'Igna. As línguas gerais sul-americanas. Papia: Revista Brasileira de Estudos Crioulos e Similares (4)2, p. 618, 1996. Disponível em: http://www.etnolinguistica.org/artigo:rodrigues-1996. Acesso em: 06 jul.2020.

RODRIGUES, Aryon Dall'Igna. Panorama das Línguas Indígenas da Amazônia. In: QUEIXALÓS \& RENAULT-LESCURE, O. (orgs): As línguas amazônicas hoje. São Paulo: IRD/ISA/MPEG, 2000. p. 15-28.

RODRIGUES, Aryon Dall'Igna. Sobre as línguas indígenas e sua pesquisa no Brasil. Ciência e Cultura, São Paulo, v. 57, n. 2, p. 35-38, 2005. Disponível em: http://cienciaecultura.bvs.br/pdf/cic/v57n2/a18v57n2.pdf. Acesso em 06 jul.2020. 